\title{
The Research on the Translation Strategies of the English Version of Mu Xin's An Empty Room from the Perspective of Diaspora
}

\author{
Lili Wang \\ School of Modern Science and Technology, China Jiliang University, Hangzhou, Zhejiang, China
}

\begin{abstract}
The successful translation and reception of Chinese contemporary fictions, to a large extent, based on the choice of translation strategies taken by translators. This article takes the English version of Mu Xin's An Empty Room as an example to analyze the translator Tong Ming's translation strategies from the perspective of diaspora and how he can set up a diaspora translator model in the translation process by adhering to his four-dimensional translational standards which are difference, replacement, transplantation and art. Through a detailed comparison between the source and target text, the article aims to explore how the translator can achieve a culturally dynamic balance between domestication and foreignization strategies.
\end{abstract}

Keywords: An Empty Room,Mu Xin, translation strategies, Tong Ming, diaspora, translation standards

\section{Introduction}

The Chinese government has always been committed to the overseas dissemination and promotion of literary works. As early as the early 1980s, the English translation of domestic works in the "Panda Series" series has been published in more than 150 countries and regions and has been widely welcomed by foreign readers. Over a long period of time, the successful broadcasting of Chinese literature has interested numerous people to learn more about Chinese literature.

In recent years, Chinese authorities have spared no efforts to promote the overseas broadcasting of Chinese modern and contemporary literature to enhance the appeal and influence of Chinese culture in the world.

For example, in 2010, the National Social Science Foundation funded the application of Chinese academic translation projects;in 2011, the promulgation and implementation of "the Decision of the CPC Central Committee on Several Major Issues concerning Deepening the Reform of the Cultural System and Promoting the Great Development and Prosperity of Socialist Culture" has been carried out; In 2012, the Ministry of Education established the Publication and research funding of Translated works in the "Public Relations Project of Philosophy and Social Sciences Research". The formulation, promulgation and implementation of a series of policies have undoubtedly demonstrated the determination and courage of the Chinese government to help modern and contemporary literature "go out" and enhance cultural soft power.

However, there is no denying that the translation and dissemination of Chinese modern and contemporary literature has confronted numerous difficulties and obstacles in the process of "Going out". Scholars at home and abroad generally agree that the dilemma of Chinese modern and contemporary novel translation lies mainly in the improper translation. In "A Chinese writer's Or Service: The Translation of The Contemporary Chinese Fiction into English," Hung Eva, a translator, stressed that "the quality of a Chinese Translation not only determines what a reader thinks of a Chinese writer, but also affects what he thinks of all Chinese modern and Contemporary literature." [1]Bonnie Medougall believes that the main reason for this embarrassing situation is the errors of translation strategies [2]. Professor Hu Anjiang affirmed the view, and refined the translation decision-making errors into the errors of literary texts, target readers, and translation strategies[3].

The traditional concept of translation studies believe that the biggest responsibility of a successful translator is to

ISSN: 0010-8189

(C) CONVERTER 2021

www.converter-magazine.info 
transfer the exact style of the writer, however, in recent years, it is believed that excellent translators should not only be faithful to the original text, but also take the acceptance of the target readers into consideration in order to achieve effective spread in overseas markets. Under such circumstances, how to choose the appropriate translation modes and strategies has undoubtedly become the theme of the current translation field.

\section{II.The Choiceof Translation Strategies}

Then what reasonable translation strategies should be adopted in the translation of Chinese modern and contemporary works? In this paper, Zhang Qian from Xi'an Foreign University analyzed two translation models proposed by Professor Hu Anjiang: Sinologist model [4]and Chinese-Western joint scholar model[5].

The typical representative of Sinologist model is Sinologist Howard Goldblatt. As we all know, in 2012, Chinese writer Mo Yan successfully won the Nobel Prize for literature, which can also be considered as a kind of success of the translator Howard Goldblatt. Without his efforts, it is nearly impossible for Chinese writers to get widespread impact over the globe and make the Chinese modern and contemporary novels have the opportunity to "go out", getting recognition for overseas readers and critics. However, Goldblatt's translational works mainly based on domestication strategy give priority to the needs of target readers. Because of its non-native Chinese translator, there exist a large number of translational mistakes and even rewritten parts in the version. Goldblatt also acknowledged that, unless translators "play this game with American publishers," Chinese contemporary novels have a slim chance of being published in the U.S. market [6].

However, there are also a series of problems with the Chinese-Western joint scholar model based on the strategy of foreignization. By taking the foreignization strategy, scholars represented by Yan Xianyi and Gladys are trying their best to retain the source cultural gene of text by keeping the original ways of expressions. However, there are also some problems that cannot be omitted. The original ways of expressions may seem obscure to western readers, easy to create reading frustration for them, which is obviously not conducive to the overseas promotion of Chinese fictions.After a detailed inspection of the English translation versions of A Dream of the Red Mansion, it is not difficult to find that, compared with the translation version of Sinologist David Hawkes, Yang Xianyi's translation is far inferior to Hawkes' translation in terms of the number of readers borrowed, the number of researchers' citations, the circulation, and the number of reprints. Eoyang believes that this kind of scholar translation is not aimed at communication and is difficult to understand and readable for readers [7]. Jenner, when commenting on Australian scholar Mable Lee's translation of Gao Xingjian's Lingshan, pointed out that "there is hardly a translation that is not cumbersome.’[8]

Song Qingwei pointed out the contend of domestication and foreignization in translating current novels has important guidance to the research of translation, but in the process of "going out", more attention should be paid to the spread of Chinese culture validity, which means whether the broadcasting has realized the effective communication[9].

In the process of translation, domestication and foreignization should not be opposed. They are only two means of effective overseas dissemination of Chinese works. They complement each other and lead to the same destination. In the English translation of Chinese literary works, foreignization should be the priority, while domestication should be the secondary. It should be readable and accepted by overseas readers, and try to keep the original essence of the original text[10].

Song Qingwei proposed that translators' models and strategies should be formulated according to China's own development stage. In the period of cultural breakthrough (that is, the period that has not been widely recognized by the international community), Sinologist's mode and domestication strategy should be the main-stream. In the cultural wrestling stage (or equal communication stage), the model of Chinese native translator with Sinologist or Chinese-American translator should be adopted to lay a foundation for the classicalization of local culture. In the stage of classicalization of Chinese literature (in which Chinese literature has been widely recognized in the world),

ISSN: 0010-8189

C CONVERTER 2021

Www.converter-magazine.info 
it is necessary to adopt a translation model with local translators as the major translators, sinologists or translators should take foreignization as the main translation strategy.

\section{A Case Studyofan Empty Room in Translation Strategy}

Professor Tong Ming's English translation of Mu Xin's novel An Empty Room came into being during this period. $\mathrm{Mu}$ Xin is a successful writer who can be called scholar of both Chinese and Western cultures, and is also a contemporary avant-garde, whose writing is refined and graceful, inheriting the language charm of a long history of Chinese. "Mu Xin's Chinese style is similar with the classical style such as The Book of Songs, and well versed in the rhythm of prose novels of the Ming and Qing Dynasties and the Republic of China." [11]

In 2011, Tong Ming translated Mu Xin's collection of short stories, An Empty Room, which was first published by New Direction, a well-known American literary publishing house, and included $13 \mathrm{Mu}$ Xin's novels. (Note: The complete Chinese version (including sixteen articles) was published with the title "Bao bian(which meansthe change of the leopard in Chinese)" in 2017. The original Chinese texts analyzed in this article are all derived from this book.) After the publication of the translation, it has aroused much appreciation from overseas literary critics. Many Western book review organizations, such as Publishers weekly, The Asian Review of Books and Three Percent, have given high praise for the book. "The translator Tong Ming translated the ultimate literary nature of Mu Xin's work in this translation."[12] The translation has attracted a lot of attention in the United States, so that Publisher weekly offered a special issue for the introduction of the book and posted positive comments. Furthermore, the world-renowned publisher Penguin Group also published the book simultaneously in Canada[13].

The author aims to analyze the reasons why the famous translator Professor Tong Ming's translation of Mu Xin's collection of short stories An Empty Room can get high praise at home and abroad. The essay is aiming at analyzing the special translational strategy from the linguistic perspectives which achieves a kind of dynamic balance between foreignization and domestication strategies.

By making the full use of the three aspects of his outstanding strengths, namely bilingualism, literary accomplishment and translation competence, Professor Tong Ming realized a dynamic balance between domestication and foreignization, and has formed the four-dimensional translational standards which are difference, replacement, transplantation and art. Through the detailed analysis of the language text in the process of collision between different cultures, Tong Ming has proposed a new translational model---the diaspora translator model. By analyzing his skillful translation examples in detail, it is not hard for us to realize the advantages of the brand-new translational model----the diasporic translator's familiarity with both Chinese and foreign cultures.

\subsection{The translation strategy from the perspective of diaspora}

Professor Tong Ming first mentioned the term "Diaspora" in his famous paper, The Homeland Translation: On the Perspective in the Post-Post-Diaspora Era[11]. Diaspora is an ancient English word of Greek origin that has emerged in the post-colonial and globalization context. Since the 1970s, the term marked the emergence of a new cultural perspective. According to Tong Ming, "literary and cultural scholars can use the term to refer to the cultural phenomenon beyond the category of a single nation in the post-colonial era, as well as the changes in aesthetic and cultural judgments caused thereby.’[14]

Contemporarily, this term includes cross-cultural culture, translation and integration. For this reason, diasporic perspective often contains cross-cultural and cross-national characteristics. "It is often used to challenge some national cultural boundaries for the purpose of assimilation consciousness." [15]According to him, the concept of home from the perspective has become larger, and it is no longer the actual geographical home, but the root of the home and state in the heart.

The diasporic translators reproduce the home in the heart through the formation of cross-nationality and cultural

ISSN: 0010-8189

(C) CONVERTER 2021

www.converter-magazine.info 
translation itself is dependent on the two kinds of cultural interaction, the diasporic translator is the carrier of this kind of interaction, while the translation is no longer just the simple translation, but serves as the carrier of home root culture and history, combined with the culture of the target language interpretation of a kind of reconstruction of literature and art[16].

Walter Benjamin emphasized in The Task of the Translator that being faithful to the original text is the most important purpose of translation. The "faithfulness" of translation is not a simple and rude mechanical translation, but the translator fully demonstrates bilingual talents. In the process of cultural conversion, creative translations should be taken by the translator to accomplish the translatability of translation, and the interaction between the translation and the original text reflects the art of translation [17].

Professor Tong Ming, a representative of the diasporic translator model, argues that Benjamin's translation theory implies a paradox in the translation of literary works. According to Tong Ming, only by fully understanding the untranslatability that exists in translation can a translator possibly learn to master the art of showing the translatability of the original text [18]. Only by fully approving the "untranslatability" of translation can a translator make "translatability" become possible. Only translators and researchers can fully understand this mysterious game of words. In the opinion of researchers who agree with artistic translation, translation itself is the deep interaction of two languages, through the fusion of the two, a greater language is formed [19].

Then from the diasporic perspective, what kind of translation strategies should be adopted to better spread the cultural essence of Chinese contemporary novels? Professor Tong Ming believes that both of domestication strategy and foreignization strategies are not reliable. In the English translation practices of Chinese contemporary novels, translators should not be forced to assimilate and give up showing their own cultural differences just because overseas readers think their cultures are too foreign and hard to understand. On the other hand, translators should not be limited to their own culture and give up participating in cross-cultural and cross-cultural cultural exchanges. Because "if you can't participate in cross-cultural and cross-ethnic activities or exchanges, you can't reflect or fully show your own ethnic cultural differences, so as to realize the propagation of native culture in the foreign countries. Therefore, as a diasporic translator, the most important task is to "re-create the homeland from the starting point of mixing several cultures[20]".

\subsection{The interpretation of Tong Ming's four-dimensional translation standards}

The author will try to analyze the translation examples in Professor Tong Ming's translation of An Empty Room, and illustrate his four-dimensional translation standard based on the perspective of diasporic culture. Tong Ming, a tenured professor of English at California state university, used to be one of UN headquarters senior translators. He is an authority of Chinese literature and foreign literature, and has formed a mature view of translation because of his long-term experience in translation practices. Tong Ming incisively summed up his four-dimensional translational standards as four Homophones of "Yi", which mean "difference, replacement, transplantation and art" respectively[21].

Tong Ming mentioned, "The so-called translatability means being different, exchangeable and transplantable and artistic. In the final analysis, translatability is also a skill. Art is the fourth dimension in translation." [22] That is to say, "difference, replacement and transplantation" are three different processing techniques in translation, the ultimate ideal of which is to achieve the effect of "art".

Based on Mr. Tong Ming's four-dimensional translation standards, the author tries to analyze, from the linguistic perspective, how professor Tong Ming's translation of Mu Xin's novels can achieve a dynamic balance between domestication and foreignizationby adopting flexible translation techniques.

3.2.1 The interpretation of difference

The author believes that there are two ways to interpret the "difference" in Tong Ming's four-dimensional translation standards. The first is that the translator needs to thoroughly understand the differences between English

ISSN: 0010-8189

C CONVERTER 2021

www.converter-magazine.info 
and Chinese expressions before adopting reasonable and flexible responses in the translation process, such as adding notes or omitting some contents. Secondly, translators should be brave to show the differences between the original culture and the target culture, so as to realize the effective propagation of native culture in other countries.

The two interpretations of "difference" involve two different translation strategies: domestication and foreignization. The first type of "difference" refers to flexible translations, which is subordinate to the strategy of domestication. The application of the first kind of "difference" makes the original text more readable through reasonable additions or omissions, while the second type of "difference" takes the opposite strategy and belongs to the strategy of foreignization. While the translator tries to retain the original charm of the original text, the translated version will give target readers a sense of exoticism and freshness.

Example 1:I found his words quite noble and praised him. "I may have taught you piano but I could never have taught you this lesson. You're obviously your own teacher - and no nightingale from the nineteenth century."[23] (Since the following examples of the translated version are all quoted from this book, the author will indicate the name of the book and the number of pages in the other examples.)

The source text: wo hen xi huan ta de lang da, kua jiang dao: "jiao guo ni gang qin, mei jiao guo ni zhe xie, wi shi zi tong, dao di bu shi shi jiu shi ji de ye ying le."[24](Due to publication problems, the Chinese citations in this article are all presented in the form of Mandarin phonetic symbols. Readers who are interested in the topic of research can find the Chinese expression of the citations on the pages indicated by the author.Since the following examples of the source text are all quoted from this book, the author will indicate the name of the book and the number of pages in the other examples.)

Here is an excerpt from the short story Fang Fang No.4 in An Empty Room. The translator takes full account of the differences in expression between English and Chinese. Secondly, most Chinese sentences have no subjects, while English sentences must have subjects. The translator should pay attention to adding personal pronouns "I" and "you" in translation, and adding possessive pronoun "your" in the expression of "wu shi zi tong", which undoubtedly makes the writing more consistent with English writing customs. This is the first standard "difference".

It is worth noting that in the translation of An Empty Room, the translator not only pays attention to the conjunctions and pronouns which are easy to be missed when translating from Chinese to English, but also makes up the unsaid words implied by the author according to the actual situation.

Example 2: And despite the gender difference, they dragged me along when they went shopping for dresses and shoes as they respected my opinions in such matters. (An Empty Room, Mu Xin, 2011:33)

The source text: "sui ran nan nv you bie, ta men tian zhi yi lv, la wo yi tong qu pin ping xuan ze....."(BaoBian, Mu Xin, 2017: 71)

Here the translator added "as they respected my opinions in such matters" according to the context to explain clearly to the target language readers why they pulled me away because they "respect my opinions on these matters", making the full text read more fluent and natural, which perfectly realizes the flexible conversion of English and Chinese languages.

Example 3: Mountain dwellers call azaleas "red reflections of the mountains." Azaleas-mostly red ones, some white-were in full bloom.(An Empty Room, Mu Xin, 2011:11)

The source text: du juan hua, shan li jiao "ying shan hong” ye you bai de, kai de zheng sheng. (Bao Bian, Mu Xin, 2017: 50)

ISSN: 0010-8189

C CONVERTER 2021 
This sentence is short, but the translator here shows the dual "difference" technique. In the first sentence, the author fully considers the different expressions between English and Chinese to translate "shan li"into "Mountain dwellers"which refer people who live in the mountains. Secondly, another "difference" is based on foreignization strategy to translate "shan li hong" literally as "red reflections of the mountains"to retain the exotic flavor of the original expression.

In Mu Xin's novel, the use of such "difference" techniques based on foreignization strategies is very common. There are many mysterious and incomprehensible Buddhist events and related theoretical descriptions in the text, such as "shu tou", "yin jian", “yang jian”, and so on. In order to avoid lengthy explanation, the translator adopts the translation standard of "difference", using transliteration, literal translation, and literal translation with annotations to translate these culturally specific terms to retain the aesthetic value in the original work and also arouse readers' curiosity to learn more, and encourage interested readers to explore the profound meaning by themselves.

3.2.2 The interpretation of replacement

Example 4: As far as I could explain then, shu-tou was the written penance sent to the dead ancestors "by water route and by land route" ..... as if it were a grand drama acted out in sequential segments with monks reciting the scriptures and kowtowing on the grand. (An Empty Room, Mu Xin, 2011:4)

The source text:"shu tou"zhe xian zai wo neng jie shi wei da xing jing chan "shui lv dao chang"de shu mian zong jie......cheng xu geng fan ru de ru yi ben lian ben da xi.(Bao Bian,Mu Xin,2017:14)

The translation here is based on the domestication strategy, using the translation technique of replacement, creatively combined with the text, the translator explains "shu mian zong jie" into "the written penance" which can be understood by the West readers. Furthermore, "lian ben da xi" was translated as "a grand drama". "shui lu dao chang" was translated into "by water route and by land route, the entire rite". The series of organic combination of foreignization and domestication translation strategy of "difference" and "replacement", enables "the translator maximally keep the source language culture and help target readers comprehend." [25]

Another way of interpreting "replacement" is even more interesting. The translator can use similar expressions in the target language to "replace" the expression in the source language. The familiarity of culture makes this "easy" method in the text possible.

Example 5: I waved a "No thanks" ...... I felt a pang of regret. I didn't think it would take so long. (An Empty Room, Mu Xin, 2011: 11)

The source text:wo yao yao shou.....xin li ao hui, wo bu zhi dao shang shan xia shan yao hua zhe me chang shi jian.(Bao Bian,Mu Xin,2017:50-51)

This example shows that the translator has a good grasp of both languages. Replacing the eastern gesture "yao yao shou" with western gesture "waved "No thanks" will undoubtedly make the translated version seem more spontaneous and acceptable.

The standard "replacement" has been applied to the translation of for numerous times, such as "zhu chi" is translated as "the leading monk", "gong de yuan man" is translated as "be completed in a formal fashion", and "yin feng nong yue" can be translated as "sentimental poems weaken your will". Furthermore, the famous line of Chinese ancient poem "ren mian tao hua xiang ying hong" is vividly and poetically translated into "a pink face mirroring a peach blossom".

Those idiomatic translations have help achieved an accurate and appropriate cultural conversion in the target text.

ISSN: 0010-8189

(C) CONVERTER 2021 
In the translation process, based on domestication strategy, "replacement" is frequently adopted by the translator to reduce readers' reading barriers, which greatly enhances the readability of the translation.

3.2.3 The interpretation of transplantation

Example 6:She looked more like, well, a flower. Sister and I made faces behind her back, and called her "a social flower", knowing it wasn't very nice of us to say that. (An Empty Room, Mu Xin, 2011:16)

The source text:er qie ta yi dian ye bu xiang ge mu qin, xiang duo hua, wo he jie jie bei di jiao ta "jiao ji hua", tu tu she tou, si hu zhe shi bu ying gai shuo chu sheng lai de.(Bao Bian,Mu Xin,2017:54)

Like the previous example, this paragraph is also a combination of multiple translation techniques, which involve "different", "exchangeable" and "transplantable". First of all, the translator fully considered the differences between English and Chinese expressions to omit the "mother" part, and adopted the expression mode of "more like" and the image of "flower" in the source language to emphasize the characteristics of Ms. Xia Mingzhu as "flower".

In translating "jiao ji hua", the translator can directly use an authentic expression in target language as "social butterfly", but gave up the "exchangeable"choice to use the above-mentioned "flower" image. Combined with the translation of "a social flower", it is not difficult to understand for the target readers to realize the connotation and also achieve the effective transplantation of the original image in the target language.

In this paragraph, the translator flexibly switches between domestication and foreignization strategies according to different needs. For example, Tong Ming chooses to translate "tu she tou" into "make faces", and translate "gao cai sheng" into "top graduate", while "qian ji ming" is translated as "one of three with the highest GPA" and so on.

Due to the familiarity of the target culture as a diasporic translator, these expressions sound familiar to Western readers, which realizes the cultural "transplantation" and helps readers to understand the connotation of the source language more easily.

The focus here is the application of the technique of "transplantation". The author believes that "transplantation"is the third dimension which goes beyond "difference" and "replacement". It does not mean that the translator simply adopts the method of transliteration or literal translation to force concepts of one culture into another. A successful cultural conversion can never be achieved simply by the translator's bilingual skills or cultural proficiency to use the authentic expressions in the target language to replace the expressions in the source language, but only can be possibly achieved when the translator can, in the process of inter-language conversion, artistically and spiritually adopt the original charm, such as original images or special expressions.

The ultimate goal of any translator is to "reproducing the style of the old country in another language and culture"[26]. The realization of the "migration" reconstruction means that the culture can be dispersed and multiplied.

Therefore, it can be said that, only when a translator can fully understand the "difference" of two cultures and be flexible to "replace", then it is possible for him or her to achieve a successful transplantation in the target culture [27].

The technique of "transplantation" is a very important link in the process of inter-lingual conversion that it can served as a severe test for the translator about the artistic imagination and bilingual proficiency. Even as a superb translator, Professor Tong Ming sometimes finds it is so hard to make a successful conversion of cultures, he points out, "whether can a translator be called as an artist depends on patience and meticulousness, self-cultivation and spirituality, and a little luck. With all of them it is possible for him to summon the brush of the gods." [28]

ISSN: 0010-8189

(C) CONVERTER 2021 
Example 7: Our family teacher was an erudite scholar who had passed the imperial exam of the Manchu Dynasty with high honors. I was a piece of stone too hard to be carved into any desired shape. (An Empty Room, Mu Xin, 2011:7)

The source text: jia ting jiao shi shi qian qing zhong ju de bao xue hong ru, wo que shi kuai luan dian tou de wan shi, yi mei fu yan du ri.(Bao Bian,Mu Xin,2017:47)

Although this paragraph is short, it also involves three standards, "difference", "replacement" and "transplantation". Firstly, in the dimension of "difference", the translator also took into account the standard in the conversion between Chinese and English, and appropriately added the omitted tense in Chinese, and adopted the past perfect tense "had done". Secondly, in the dimension of "replacement", the translator translates "hong ru" into "scholar" and "qian qian Zhong ju" into "pass the imperial exam of the Manchu Dynasty with high honors", which not only explains the background of the characters, but also adopts a way of expression that is easier for Western readers to understand.

Furthermore, in Example 7, the translator applies the "transplantation" standard to translate the concept of "wan shi”. In the original text, "wo shi kuai luan dian tou de wan shi”has a rich meaning in Chinese context. A Dream of Red Mansions, one of the four great Chinese masterpieces, is also known as The Story of the Stone. It is a story about the experiences of the hero Jia Baoyu whose nature is a stone. The image of "stone" is very appropriate in the original text. Although there is no related expression in English culture, the translator does not abandon this significant image and translates the whole sentence into "I was a piece of stone too hard to be carved into any desired shape", which can tell the reader that the "stone" here is just a metaphor.

Through this way, the special image of "stone" in the source culture is successfully transplanted into the context of the target language. In the translation of the whole sentence, based on the image of "hard stone", the original text of "nodding head in disorder" was abandoned, and it was reasonably changed into "too hard to be carved into any desired shape" that matched the image of legendary stone in Chinese culture. The Chinese expression "when jades can't be polished, it can't be a tool; when people can't learn manners, they don't know how to be polite". The successful conversion achieves semantic coherence and achieves excellent translation effects. Reading Tong Ming's version will surely make readers dreamy and has endless aftertastes.

\subsubsection{The Interpretation ofArt}

As for the fourth dimension of translation standard "art", it can be called the "the real challenge for a translator doesn't lie in his ability to deal with the difficulties that others can find out, but in his ability to do the transformation that others usually cannot. The real difficulty lies in how he seeks the same essence from the different languages, achieves the cultural equivalences in the exchangeable and transplantable process to achieve the ultimate artistic effects. What the translator really knows can never be showed directly but only conveyed to the readers."[29]

Example 8: Spring doesn't arrive so easily. Spring is like a melancholy yet dignified man. (An Empty Room, Mu Xin, 2011:99)

The source text: chun tian bus hi zhe yang qing yi lai, hen xiang ge yong rong chou chang fu xie de ren.(Bao Bian,Mu Xin,2017:141)

In accordance with the rhythm of English meaning group, the translated version can be divided into Spring/does not arrive/so easily/and Spring/is like/ a dignified/ yet dignified/man, which not only completes the syntax neatly, but also artistically forms the rhythm equally. Even Mr. Tong Ming couldn't help feeling that he was so lucky to get such an artistic translation that perfectly matched the original text. Furthermore, it is so hard to achieve the 
rhythm of the whole text, and it is often necessary to change the manuscripts for many times.

Example 9:Mountains, now refreshingly green in the distance, blurred in the water reflections. A mild breeze caressed my face. Where was my mother? (An Empty Room, Mu Xin, 2011:12)

The source text:liang an shan se cang cui, shui li de dao ying xian huo shan niao. Ying mian de feng you liang younuan, mu qin wei shen me bu lai.(Bao bian,Mu Xin,2017:51)

The translation here is superb. Mu Xin's words are refined and very poetic. Professor Tong Ming's sentences are also very beautiful. They have both rhythm and vivid words, such as "refreshingly green" and extremely rich. The dynamic beauty of the diction "blurred" undoubtedly shows the profound literary skills of the translator. The translation work of Mu Xin's novel began in 1993 and lasted for more than 20 years. It was assembled and published in 2011 and received great acclaim in the English-speaking world. During the period, only the translator himself knows how hard it is. When Mu Xin saw the translated version finally, he happily called it "my mixed-blood child" and proposed that "creation is fatherly, while translation is motherly", which is undoubtedly the highest recognition of Professor Tong Ming's translation [30].

Through the above-mentioned examples, it is not hard for us to realize "creation is the father, translation is motherhood", which was pointed out by the author when he read final translational version given by Tong Ming. Since maternal characteristics lie in the infinite patience, excellent translators need to have unlimited patience to handled carefully each sentence in translation practices so as to understand the author original intention and achieve ultimate faithfulness in translation by adopting reasonable translation strategies and techniques. As a good translator, there is no other choice but to continuously deepen his literary and artistic accomplishment so as to have more chances to get inspirations in his translations.

\section{Conclusion}

Through the detailed analyses of the above-mentioned translation practices, the readers can fully understand that in the process of Chinese modern and contemporary novel translation, how much contributions have been done by the translator Tong Ming to adjust measures dynamically and flexibly to accord with various conditions in order to make the translation not only fully demonstrate the essences of Chinese culture, but also effectively smooth the reading experiences of the western readers. Only by adhering to this kind of flexible and effective translation modes and strategies can Chinese culture have chances to enhance its cultural influence overseas and let more and more Western readers learn to understand and appreciate the essences of Chinese culture.

\section{Acknowledgements}

His paper is supported by Zhejiang Provincial Department of Education in 2019 with the title "The Translator Modes and Strategies of Chinese Contemporary Novels" (Project No.Y201942290).

\section{References}

[1] E.Hung. "Blunder or service: the translation of the contemporary Chinese fiction into English,’Translation Review, no.36, pp. 39, 1991.

[2] B. Medougall. "Literary translation: the pleasure principle," Chinese Translation, no. 5, pp. 45, 2007.

[3] A. J.Hu. "Translator model, translating strategy, and the "going out" project to promote Chinese literature abroad: with American Sinologist Howard Goldblatt as an example," Chinese Translators Journal, vol. 6, pp. 10-16, 2010.

[4] A. J. Hu. "Translator model, translating strategy, and the "going out" project to promote Chinese literature abroad: with American Sinologist Howard Goldblatt as an example," Chinese Translators

ISSN: 0010-8189

(C) CONVERTER 2021 
Journal, vol. 6, pp. 10-16, 2010.

[5] A. J.Hu, C. F. Hu. "The translator model and the translating strategy revisited — with the dissemination of cold mountain poems in the English world as an example,"Foreign Language Learning Theory and Practice, vol. 4, pp. 55-61, 2012.

[6] H. Goldblatt. "Of silk purses and sow's ears: features and prospects of contemporary Chinese fictions in the west,"Translation Review, no.59, pp. 26, 2000.

[7] E. C.Eoyang. "Borrowed plumage: polemical essays on translation,” New York: Rodopi,pp. 56, 2003.

[8] W.J.F. Jenner, "Heading for the hills,"Times Literary Supplement, no.5110, pp. 54, 2001.

[9] Q. Zhang. “An exploration of the flying translator model of Chinese literature going out--taking tong ming's translation of mu xin's short stories an empty room as an example," Foreign Language Teaching, no. 5, pp. 106, 2015.

[10] Q. D.Lu. "The cultural diasporic journey of mu xin's short stories in the English-speaking world," Chinese Translators Journal, no. 1, pp. 76, 2004.

[11] M. Tong. "Diaspora," Foreign Literature, no. 2, pp. 119, 2004.

[12] Q. W. Song."The enlightenment of mo yan's novel translation on the "going out" of Chinese literature,’Shangdong Social Sciences, no. 11, pp. 177, 2018.

[13] Q. W.Song. "The enlightenment of mo yan's novel translation on the "going out" of Chinese literature,’Shangdong Social Sciences, no. 11, pp. 180, 2018.

[14] M. Tong. "The homeland translation: on the perspective in the post-post-diaspora era,"Comparative Literature in China, pp. 151, 2005.

[15] M. Tong. "The homeland translation: on the perspective in the post-post-diaspora era," Comparative Literature in China, pp. 152, 2005.

[16] M. Tong. "The homeland translation: on the perspective in the post-post-diaspora era," Comparative Literature in China, pp. 160, 2005.

[17] W. Benjamin. "The task of translator", illuminations: essays and reflections," Trans. Harry Zohn, Ed. Hannah Arndt, New York: Schocken, pp. 69-71, 1969.

[18] M. Tong. "The homeland translation: on the perspective in the post-post-diaspora era," Comparative Literature in China, pp. 150, 2005.

[19] W. Benjamin. "The task of translator", illuminations: essays and reflections," Trans. Harry Zohn, Ed. Hannah Arndt, New York: Schocken, pp. 69-71, 1969.

[20] M. Tong. "The homeland translation: on the perspective in the post-post-diaspora era," Comparative Literature in China, pp. 161, 2005.

[21] M. Tong. "Diasporic culture and literature," Foreign Literature, no. 1, pp. 119, 2007.

[22] M. Tong. "Diasporic culture and literature," Foreign Literature, no. 1, pp. 120, 2007.

[23] X.Mu. “An empty room,” Translated by Tong Ming. New York: New Directions, pp. 35, 2011.

[24] X. Mu. B. Bao. Guangxi Normal University Press, vol. 10, pp. 73, 2017.

[25] Q. D.Lu. "The cultural diasporic journey of mu xin's short stories in the English-speaking world," Chinese Translators Journal, no. 1, pp. 78, 2014.

[26] M. Tong. "Diasporic culture and literature," Foreign Literature, no. 1, pp. 119, 2007.

[27] Q. D. Lu. "The cultural diasporic journey of mu xin's short stories in the English-speaking world," Chinese Translators Journal, no. 1, pp. 77, 2014.

[28] M. Tong. "Cosmopolitan aesthetic thinking revives Chinese literature — the significance of mu xin's style,” China Book Review, no. 8, pp. 7, 2006.

[29] M.Tong. "The homeland translation: on the perspective in the post-post-diaspora era," Comparative Literature in China,pp. 162, 2005.

[30] X. Mu. B. Bao. Guangxi Normal University Press, vol. 10, pp. 22-23, 2017. 